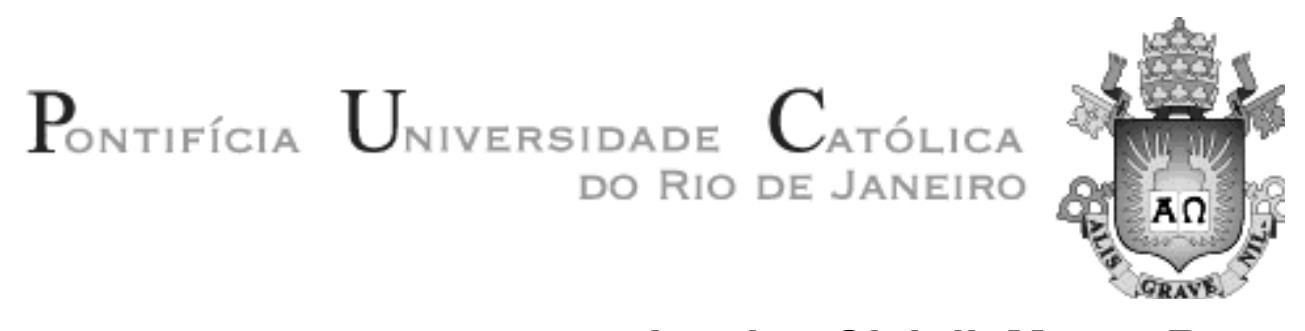

Janaina Oleinik Moura Rosa

Um Estudo de Compactação de Dados para

Biosseqüências

Dissertação de Mestrado

Dissertação apresentada como requisito parcial para obtenção do título de Mestre pelo Programa de PósGraduação em Informática da PUC-Rio.

Orientador: Sérgio Lifschitz 


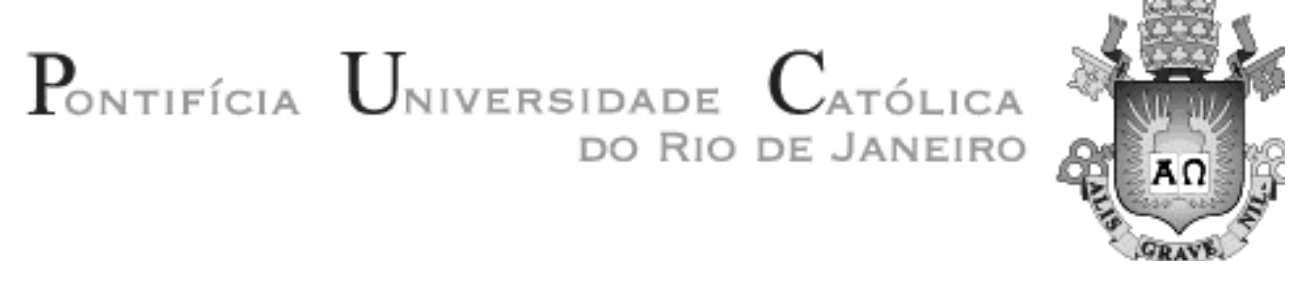

Janaina Oleinik Moura Rosa

\section{Um Estudo de Compactação de Dados para \\ Biosseqüências}

Dissertação apresentada como requisito parcial para obtenção do título de Mestre pelo Programa de Pós-Graduação em Informática da PUC-Rio. Aprovada pela Comissão Examinadora abaixo assinada.

Sérgio Lifschitz

Orientador PUC-Rio

Fernanda Araújo Baião

UNIRIO

Luiz Fernando Bessa Seibel

PUC-Rio

Rubens Nascimento Melo

PUC-Rio

Prof. José Eugenio Leal

Coordenador(a) Setorial do Centro Técnico Científico - PUC-Rio

Rio de Janeiro, 6 de setembro de 2006 
Todos os direitos reservados. É proibida a reprodução total ou parcial do trabalho sem autorização da universidade, da autora e do orientador.

\section{Janaina Oleinik Moura Rosa}

Graduou-se em Engenharia Informática na Universidade Católica "Nstra. Sra de la Asunción", PY, em 1998. Atuou em empresas como Analista de Sistemas e Administrador de dados. Lecionou no curso de Administração e Tuning de Banco de Dados do CCE PUC-Rio.

Ficha Catalográfica

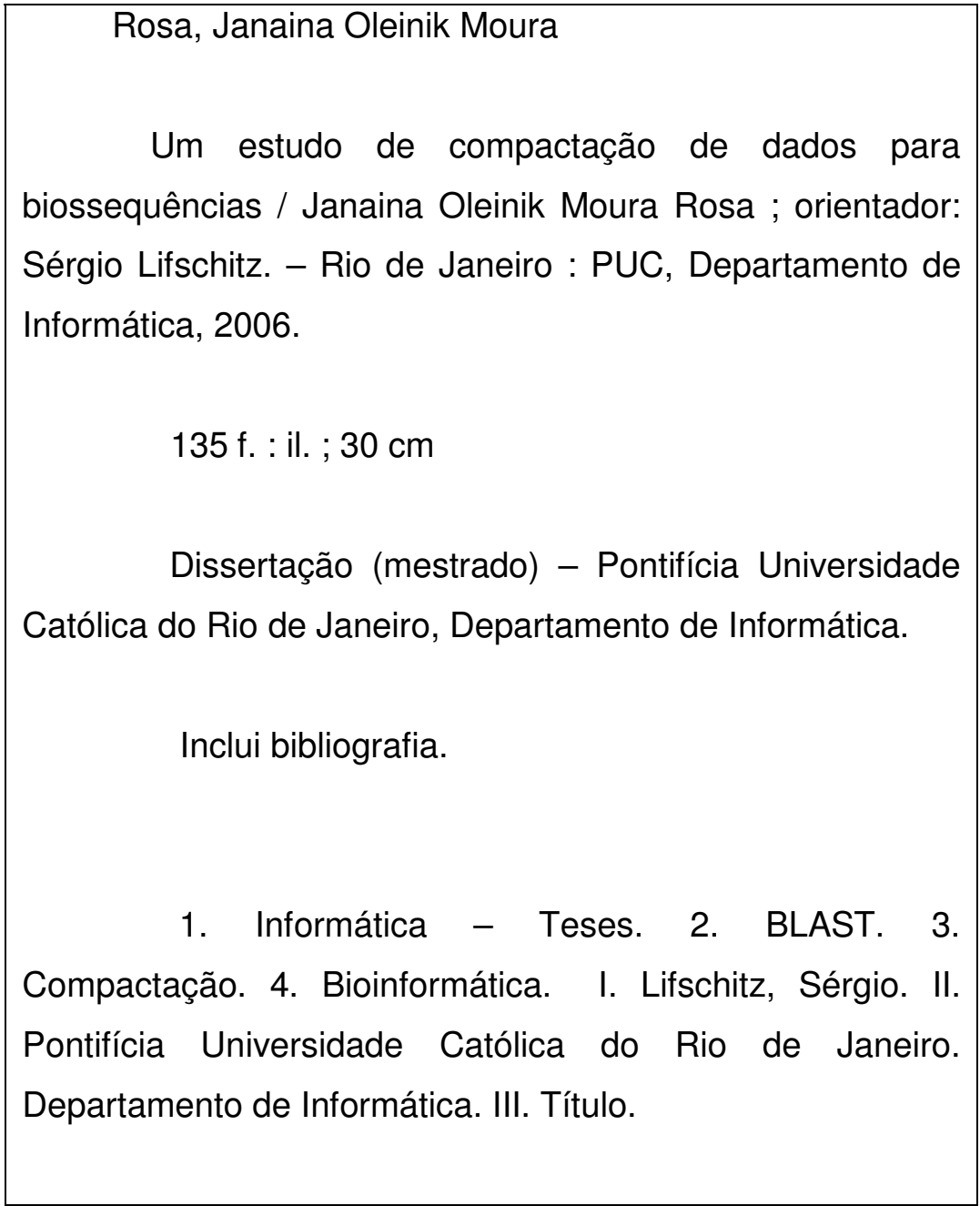

CDD: 004 
Aos meus pais pelo apoio incondicional. Ao meu marido, José Antônio, por incentivo e carinho constantes. $E$ ao meu pequeno Antônio que chegou para dar mais alegria e motivação. 


\section{Agradecimentos}

Ao professor Sérgio Lifschitz pela orientação e empenho na leitura e revisão do texto.

Ao professor Eduardo Laber pela colaboração com materiais e dicas sobre algoritmos de compressão de dados.

Ao meu marido José Antônio pelas inúmeras contribuições ao trabalho. Suas revisões e orientações foram fundamentais. Agradecimentos pela companhia carinhosa, mesmo que virtual em alguns momentos, não importando nem mesmo o fuso-horário. E principalmente por acreditar que seria possível.

Ao amigo Eduardo Morelli pelo companheirismo e amizade desde as primeiras disciplinas até a entrega deste documento, e principalmente pelas palavras otimistas nos momentos difíceis.

À amiga Michelle, pelo seu ponto de vista sempre tão prático e espirituoso.

Aos amigos Simone, Ciro e Maíra pelos momentos de descontração.

À minha família, meus pais, Rui e Leila, e irmãos, Ruizinho, Rafaela e Gabriela pelo amor e apoio incondicional em todos os momentos.

Ao meu filho Antônio que trouxe motivação e alegria extras na reta final. 


\section{Resumo}

Oleinik Moura Rosa, Janaina; Lifschitz, Sérgio. Um Estudo de Compactação de Dados para Biosseqüências. Rio de Janeiro, 2006. 135p. Dissertação de Mestrado - Departamento de Informática, Pontifícia Universidade Católica do Rio de Janeiro.

A família de algoritmos BLAST é a mais utilizada pelos biólogos para a busca de similaridade entre biosseqüências, e por esta razão, melhoras nestes algoritmos, em suas estruturas de dados ou em seus métodos de acesso à memória secundária são muito importantes para o avanço das descobertas biológicas. Nesta dissertação, foi estudada detalhadamente uma versão do programa BLAST, analisando as suas estruturas de dados e os algoritmos que as manipulam. Além disso, foram realizadas medições de desempenho com o intuito de identificar os possíveis gargalos de processamento dentro das fases de execução do BLAST. A partir das informações obtidas, técnicas de compactação de dados foram utilizadas como uma estratégia para redução de acesso à memória secundária com o objetivo de melhorar o desempenho para a execução do BLAST. Finalmente, foi gerada uma versão modificada do BLAST no ambiente Windows, na qual foi alterado diretamente o código do programa. Os resultados obtidos foram comparados com os resultados obtidos na execução do algoritmo original.

\section{Palavras-chave}

BLAST; compactação; Bioinformática 


\section{Abstract}

Oleinik Moura Rosa, Janaina; Lifschitz, Sérgio. A Study of Biosequence Data Compression. Rio de Janeiro, 2006. 135p. Master Thesis Departamento de Informática, Pontifícia Universidade Católica do Rio de Janeiro.

The BLAST is the sequence comparison strategy mostly used in computational biology. Therefore, research on data structures, secondary memory access methods and on the algorithm itself, could bring important optimizations and consequently contributions to the area. In this work, we study a NCBI BLAST version by analyzing its data structures and algorithms for data manipulating. In addition, we collect performance data for identifying processing bottleneck in all the BLAST execution phases. Based on this analysis, data compress techniques were applied as a strategy for reducing number of secondary memory access operations. Finally, a modified version of BLAST was implemented in the Microsoft Windows environment, where the program was directly altered. Finally, an analysis was made over using the results of execution of original BLAST against modified BLAST.

\section{Keywords}

BLAST; data compression; Bioinformatics 


\section{Sumário}

1 Introdução 13

1.1 Bioinformática e Banco de Dados 13

1.2 Objetivos da Dissertação 14

$\begin{array}{lll}1.3 & \text { Estrutura da Dissertação } & 15\end{array}$

2 Preliminares 17

$\begin{array}{lll}2.1 & \text { Contexto Biológico } & 17\end{array}$

2.2 Operações sobre Biosseqüências 18

2.3 Persistência de Biosseqüências 20

2.4 Problemas com o armazenamento de biosseqüências 21

2.5 Trabalhos relacionados 23

2.6 Conclusão 25

$3 \quad$ Análise do programa BlastP 27

3.1 Descrição do Funcionamento do BLAST 27

3.2 Descrição da implementação do NCBI-BLAST 30

3.3 Análise do desempenho 34

3.3.1 Metodologia de Análise 34

$\begin{array}{lll}3.3 .2 & \text { Análise } & 37\end{array}$

3.4 Conclusão 43

4 Compactação de dados 45

4.1 Compactação 45

4.1.1 Classificações $\quad 47$

4.1.2 Algoritmos de compressão reversível 49

4.2 Compactação em SGBDs 51

4.3 Compactação de biosseqüências 55

$\begin{array}{lll}4.4 & \text { Considerações Finais } & 57\end{array}$

4.5 Conclusão 58

$5 \quad$ Uma proposta de compactação para o BlastP 60

$\begin{array}{lll}5.1 & \text { A solução proposta } & 61\end{array}$ 
5.2 Detalhamento da Proposta de Solução 63

$\begin{array}{lll}5.3 & \text { Conclusão } & 70\end{array}$

$\begin{array}{lll}6 & \text { Resultados experimentais } & 71\end{array}$

6.1 Metodologia de análise de resultados 71

6.2 Análise de resultados 76

6.2.1 Resultados e Análises do Cenário 1- Testes de T1 a T5 77

6.2.2 Resultados e Análises do Cenário 2 - Testes de T6 a T10 82

6.3 Conclusão 86

7 Conclusão e Trabalhos Futuros 88

7.1 Revisão dos Objetivos e Resultados da Tese 88

$\begin{array}{lll}7.2 & \text { Trabalhos Futuros } & 90\end{array}$

$\begin{array}{ll}\text { Referências } & 93\end{array}$

APÊNDICE A - Características das biosseqüencias 99

$\begin{array}{ll}\text { Propriedades de uma biosseqüência } & 102\end{array}$

APÊNDICE B - Operações sobre Biosseqüencias 104

$\begin{array}{ll}\text { Comparação de seqüências } & 104\end{array}$

$\begin{array}{ll}\text { Geração de Anotações } & 106\end{array}$

$\begin{array}{ll}\text { Montagem de fragmentos } & 107\end{array}$

APÊNDICE C - Operações sobre Biosseqüencias 110

Como as biosseqüências são armazenadas 110

$\begin{array}{ll}\text { Bancos de biosseqüencias } & 111\end{array}$

Persistência em gerenciadores de bancos de dados comerciais e específicos $\quad 121$

$\begin{array}{ll}\text { Outras propostas de persistência para biosseqüências } & 124\end{array}$

APÊNDICE D - Algoritmo BWT 129

$\begin{array}{ll}\text { Exemplo } & 130\end{array}$

APÊNDICE E - Implementação da solução 131 


\section{Lista de Tabelas}

Tabela 1 - Tipos de Programas BLAST 28

Tabela 2 - Passos do Algoritmo BLAST 29

Tabela 3 - Configuração da execução do BlastP para estudo do código. 30

Tabela 4 - Dados de entrada da execução do BLAST. 39

Tabela 5 - Dados de entrada da execução do BLAST 40

Tabela 6 - Resultados da execução do BLAST com a base nr captados pelo

Tabela 7 - Resultados da execução do BLAST com a base env_nr captados pelo
AQTime.

Tabela 8 - Comparação de programas de compressão de dados 58

Tabela 9 - Configuração de Hardware e Software Básico 72

Tabela 10 - Cenários de execução $\quad 74$

Tabela 11 - Planejamento experimental 76

Tabela 12 - Configuração do testes T1 a T5 77

Tabela 13 - Resumo dos resultados para o primeiro cenário 79

Tabela 14 - Resultados do teste T1 80

Tabela 15 - Resultados do teste T2 80

Tabela 16 - Resultados do teste T3 81

Tabela 17 - Resultados do teste T4 81

Tabela 18 - Resumo dos teste T5 82

Tabela 19 - Configuração dos testes T6 à T10 82

Tabela 20 - Resultados testes T6 à T10. 84

Tabela 21- Codificação para ambigüidades na leitura de nucleotídeos 99

Tabela 22 - Lista de aminoácidos $\quad 100$

$\begin{array}{ll}\text { Tabela } 23 \text { - Matriz ordenada resultante da BWT } & 130\end{array}$ 


\section{Lista de Figuras}

$\begin{array}{ll}\text { Figura } 1 \text { - Alinhamento entre seqüências } & 17\end{array}$

Figura 2 - Módulos Principais do NCBI-BLAST 31

Figura 3 - Árvore de chamada das funções do BLAST. 33

Figura 4 - Execução do PFMon para analisar page faults do BLAST 35

Figura 5 - Exemplo da informação captada com o utilitário FileMon. 36

Figura 6 - Interface do aplicativo AQTime 37

Figura 7 - Exemplo de funcionamento da primeira e segunda fase
do BLAST.

Figura 8 - Padrão de acesso ao arquivo de seqüências em uma execução do BLAST. $\quad 40$

Figura 9 - Padrão de acesso ao arquivo de seqüências em uma execução do BLAST 41

Figura 10 - Acesso aleatório ao arquivo de seqüências em uma execução do BLAST. 42

Figura 11 - Linha de código onde são acessados os dados de uma Biosseqüências

Figura 12 - Fórmula para Cálculo de Taxa de Compressão 48

Figura 13 - Principais Componentes da Solução Proposta 62

Figura 14 - Módulos Globais 63

Figura 15 - Compactação dos Dados de Biosseqüências 65

Figura 16 - Módulo Compactador 66

Figura 17 - Seqüência das Chamadas das Funções de Compactador 66

$\begin{array}{ll}\text { Figura } 18 \text { - Gerência de Memória } & 67\end{array}$

Figura 19 - Interação entre BLAST e Gerente de Memória 69

Figura 20 - Componentes do Cenário de Execução 73

Figura 21 - Número de operações de E/S para as execuções do cenário 78

Figura 22 - Tempo de execução total para as execuções do cenário 1

Figura 23 - Número de operações de E/S para as execuções do cenário 2.

Figura 24 - Tempo total de execução para as execuções do cenário 2.

Figura 25 - Resultados da execução do teste T6 85

Figura 26 - Resultados da execução do teste T7 85

Figura 27 - Resultados da execução do teste T8 85

Figura 28 - Resultados da execução do teste T9 86

Figura 29 - Resultados da execução do teste T10 86

$\begin{array}{ll}\text { Figura } 30 \text { - Alinhamento entre seqüências } & 103\end{array}$ 
$\begin{array}{ll}\text { Figura } 31 \text { - Exemplo de intercalação na montagem de fragmentos } & 108\end{array}$

Figura 32 - Exemplo de uma seqüência guardada no DDBJ 113

Figura 33 - Arquivo ASN.1 representando uma seqüência registrada no GenBank

Figura 34 - Esquema de uma saída em XML obtida da execução do BLAST $\quad 117$

Figura 35 - Uma seqüência em um arquivo FASTA gerado pelo NCBI 119

Figura 36 - Exemplo de um arquivo de entrada para o sistema ACeDB 123

Figura 37 - Árvore de sufixo. 124

$\begin{array}{lr}\text { Figura } 38 \text { - Passos do BWT } & 129\end{array}$ 